$\overline{\text { Note }}$

\title{
Comparison of Fungi Found in Bathrooms and Sinks
}

\author{
NOBUO HAMADA* AND NIICHIRO ABE \\ Osaka City Institute of Public Health and Environmental Sciences, \\ 8-34 Tojo-cho, Tennoji, Osaka 543-0026, Japan
}

Received 27 July, 2009/Accepted 13 January, 2010

\begin{abstract}
To identify the pathogenic fungi present in bathrooms, the growth of fungi collected from the drains of bathrooms was studied at various temperatures and compared with that of fungi from kitchen sink drains. Only a small number of fungi from bathrooms and sinks grew on media incubated at $37^{\circ} \mathrm{C}$, at which temperature the fungal count was about $1 / 600$ of that at 25 ${ }^{\circ} \mathrm{C}$. Although hot water is used more frequently in bathrooms than in sinks, the fungal counts at $37^{\circ} \mathrm{C}$ were similar for bathrooms and sinks. Five species of fungus that can grow at $37^{\circ} \mathrm{C}$ and were found to grow prolifically in bathrooms were identified using DNA and morphological analysis. In both bathrooms and sinks, Exophiala dermatitidis was predominant in culture at $37^{\circ} \mathrm{C}$. Moreover, E. dermatitidis grew at $40^{\circ} \mathrm{C}$ and used surfactant as a nutrient. Thermotolerant fungi appear to inhabit bathrooms and all residential water appliances.
\end{abstract}

Key words : Bathroom/Drain / Pathogenic fungus / Thermotolerant.

Japanese bathrooms are maintained under hot and humid conditions for long periods irrespective of the season. Much evaporated and condensed moisture flows down onto the bathroom floor. These bathroom conditions promote fungal growth and biodeterioration (Moriyama et al., 1992). Especially severe fungal contamination in bathrooms occurs in drains, which emit odors and are reported to be the dirtiest areas and to contain dark slime (Hamada and Abe, 2008). Drains are thus thought to be a hot spot for fungal contamination in bathrooms.

Fungal contamination in bathrooms is apparently proportional to the quantity of moisture and soap used for bathing (Hamada and Fujita, 2000). Exophiala sp., Cladosporium sp., Phoma sp., and Scolecobasidium sp., which have dark hyphae, are found predominantly in bathrooms (Hamada and Abe, 2008); Exophiala sp. and Scolecobasidium sp. are rarely found in either outdoor or other indoor environments. Moreover, these fungi seem to use the nonion surfactant component of detergents as a nutrient (Hamada, 2005).

Some species of Exophiala found in bathrooms are

*Corresponding author. Tel: +81-6-6771-3108, Fax : +816-6772-0676, E-mail: n-hamada (a) city.osaka.Ig.jp. reportedly thermotolerant (Nishimura et al., 1987) and can grow at $40-50^{\circ} \mathrm{C}$ (Zak and Wildman, 2004). Moreover, fungi growing at $37^{\circ} \mathrm{C}$ are often thought to be pathogenic and harmful to health. Bathtub water has a temperature of around $40^{\circ} \mathrm{C}$ and bathrooms would therefore be expected to be hotbeds of these thermotolerant microbes. However, as reported previously (Hamada and Abe, 2009), the predominant fungi collected from the walls and floors of bathrooms are generally thermo-sensitive.

We are interested in the physiological characteristics of fungi growing in bathrooms. No previous report has focused on the effects of temperature on the growth of the various fungi found in bathrooms and no investigation has yet been carried out into whether thermotolerant fungi are more common in bathrooms than in other environments.

For the present study, fungi were collected from the drains of bathrooms and sinks in 62 dwellings on the outskirts of Osaka during September and October 2008. The collected samples were cultured not only at $25^{\circ} \mathrm{C}$, but also at $37^{\circ} \mathrm{C}$. The fungi which grew well under high-temperature conditions were examined to ascertain their physiological features.

A swabbing kit with a cotton tip (Pro-media ST-15; Elmex) was used to collect samples from the drains, 
as described previously (Hamada et al., 2003). A 10 $\mathrm{cm}^{2}(1 \mathrm{~cm} \times 10 \mathrm{~cm})$ section of the drain surface was swabbed once with a cotton tip under constant pressure and at low speed, after which the tip was placed in solution in the kit bottle. The kit containing the sample was stored in a refrigerator and examined within a few days, when the dirty matter that adhered to the cotton tip was observed and its degree evaluated.

After been shaken, the suspension in the kit was used for cultivation. If necessary, the suspension was diluted 10, 100, or 1,000 times for counting the fungal colonies. A $0.5-\mathrm{ml}$ aliquot of the diluted suspension was poured and spread on each of two Petri dishes with $25 \mathrm{ml}$ of 1/4PDA (Potato-Dextrose Agar) medium containing $50 \mathrm{mg}$ of chloramphenicol/L (Hamada and Abe, 2008).

After inoculation, the media were cultivated at 25 ${ }^{\circ} \mathrm{C}$ for $8-10$ days or at $37^{\circ} \mathrm{C}$ for 14 days with the Petridishes wrapped in plastic bags to prevent drying of the media. The total number of CFU of fungi detected on the samples from the drains was examined and the genera of the counted mold colonies were identified as described in a previous report (Hamada and Abe, 2008). Although yeast was not examined in the present study, yeast containing Rhodotorula sp. was often detected in samples from bathrooms and sinks cultured at $25^{\circ} \mathrm{C}$.

Before the fungal counts were converted to a logarithmic scale, each count was increased by 10 for those cultured at $25^{\circ} \mathrm{C}$ and by 1 for those cultured at $37^{\circ} \mathrm{C}$, which were the detection limits. The logarithmic averages of the counts are calculated in the attached tables. The relationship between the fungal counts detected at $25^{\circ} \mathrm{C}$ and at $37^{\circ} \mathrm{C}$ was examined statistically using Pearson's coefficient, with $\mathrm{P}<0.05$ designated as representing a significant correlation.

Of the fungal strains from bathrooms or sinks detected on 1/4PDA media cultured at $37^{\circ} \mathrm{C}$, those which were present at more than $100 \mathrm{cfu} / \mathrm{cm}^{2}$ were isolated and transplanted onto slants. After each strain was precultured for 2-3 weeks, the 13 strains of collected fungus were cultured at $40^{\circ} \mathrm{C}$ for 14 days to examine their growth features and the strains were identified by their genetic and morphological characteristics.

Genomic DNA from each mycelium sample was extracted and purified (QIAamp DNA Stool Mini Kit; Qiagen $\mathrm{GmbH}$, Hilden, Germany) according to the manufacturer's instructions and PCR was performed as reported previously (Hamada et al., 2006) using the ITS1 and ITS4 primers, which amplify the region of the internal transcribed spacers 1 (ITS1) and 2 (ITS2) including the 5.8S ribosomal RNA gene (5.8SrDNA). The PCR products were gel-purified
(QIAquick Gel Extraction Kit; Qiagen GmbH, Hilden, Germany) and sequenced (ABI PRISM BigDye Terminator Cycle Sequencing FS Ready Reaction Kit; PE Applied Biosystems, Foster City, California) on an ABI 3130 automated sequencer (PE Applied Biosystems). The sequencing was carried out in both directions using the primers described above. Homology searching of the sequences obtained was performed using the FASTA program on the DNA Data Bank of Japan (DDBJ) website (http://www.ddbj.nig.ac.jp/search/fasta-j.html). The sequences of the isolates obtained in the present study were deposited in the DDBJ under accession nos. AB498917-4989227 and the corresponding voucher cultures were also deposited in the JCM (Microbe Division/Japan Collection of Microorganisms, RIKEN BioResource Center, Wako, Saitama).

After being precultured, spore blocks of $E$. dermatitidis were collected with a sterilized pin and diluted 10,000 times. The suspensions of these spores were then inoculated onto various surfactant media, as described previously (Hamada and Abe, 2008).

Three components of common commercial detergents were used as culture media: SO (sodium oleate), a sodium fatty acid and a major component of soap; AE (polyoxyethylene (9) lauryl ether), a nonion surfactant and a component of shampoo; and LAS (sodium dodecyl (=lauryl) benzenesulfonate), an anion surfactant and also a component of shampoo. The three surfactant components were adjusted to concentrations of $0.01 \%, 0.05 \%$, and $0.25 \%(0.10$ $\mathrm{g}, 0.50 \mathrm{~g}, 2.5 \mathrm{~g} / \mathrm{L}$ ) and added to $15 \mathrm{~g} / \mathrm{L}$ of Bacto-agar to compare the nutrient effect on the growth of $E$. dermatitidis. The fungi inoculated onto the media with the various surfactants were cultured at $25^{\circ} \mathrm{C}$ for 12 16 days.

Mold counts in the samples from bathroom drains and from sinks ranged from less than $10 \mathrm{cfu} / \mathrm{cm}^{2}$ to more than $10^{5} \mathrm{cfu} / \mathrm{cm}^{2}$ in culture at $25^{\circ} \mathrm{C}$. There was only one bathroom sample with a count of less than $10 \mathrm{cfu} / \mathrm{cm}^{2}$ but there were 17 sink samples (Table 1).

Mold counts in cultures grown at $37^{\circ} \mathrm{C}$ were much lower than in those cultured at $25^{\circ} \mathrm{C}$. In the former group, for example, the number of bathroom samples with a count of less than $1 \mathrm{cfu} / \mathrm{cm}^{2}$ (detection limit) was 30 and no sample with a count of more than $10^{4}$ $\mathrm{cfu} / \mathrm{cm}^{2}$ was detected among either the bathroom drain samples or the sink samples.

The swabbing kit samples collected from bathrooms were dirtier than those from sinks (data was not shown).

The average mold count in bathroom samples 
TABLE 1. Distribution of fungal contamination in samples

\begin{tabular}{lccc}
\hline Temperature & Mold count & $\begin{array}{c}\text { Bathroom } \\
\text { Sample\# }\end{array}$ & $\begin{array}{c}\text { Sink } \\
\text { Sample\# }\end{array}$ \\
\hline \multirow{3}{*}{$25^{\circ} \mathrm{C}$} & $<10$ & 1 & 17 \\
& $10-99$ & 4 & 13 \\
& $100-10^{3}$ & 15 & 11 \\
& $10^{3}-10^{4}$ & 15 & 13 \\
& $10^{4}-10^{5}$ & 26 & 7 \\
$37^{\circ} \mathrm{C}$ & $10^{5}-$ & 1 & 1 \\
& $<1$ & 30 & 27 \\
& $1-9$ & 12 & 15 \\
& $10-99$ & 12 & 13 \\
& $100-10^{3}$ & 7 & 5 \\
& $10^{3}-$ & 1 & 2 \\
\hline
\end{tabular}

The mold count and the number of samples in each category are shown.

The detection level of the mold count was $10 \mathrm{cfu} / \mathrm{cm}^{2}$ at $25^{\circ} \mathrm{C}$ and $1 \mathrm{cfu} / \mathrm{cm}^{2}$ at $37^{\circ} \mathrm{C}$. cultured at $25^{\circ} \mathrm{C}$ was $3190 \mathrm{cfu} / \mathrm{cm}^{2}$, which was more than 10 times the $244 \mathrm{cfu} / \mathrm{cm}^{2}$ average in sink samples (Table 2). In contrast, the average detected at $37^{\circ} \mathrm{C}$ was $5.0 \mathrm{cfu} / \mathrm{cm}^{2}$ in bathrooms and $5.9 \mathrm{cfu} / \mathrm{cm}^{2}$ in sinks; no difference was thus found in the average values of bathroom and sink samples. The ratio of the mold counts detected at $37^{\circ} \mathrm{C}$ to those at $25^{\circ} \mathrm{C}$ was about 1:600 in bathrooms and about 1:40 in sinks.

The relationship between mold counts detected in culture at $25^{\circ} \mathrm{C}$ and at $37^{\circ} \mathrm{C}$ was examined (Fig. 1). A significant correlation was not recognized in the mold counts of bathroom samples $(0.1>P>0.05)$, but was found between sink samples cultured at the different temperatures $(P<0.001)$.

We examined the fungal flora of bathrooms in samples cultured on medium at $25^{\circ} \mathrm{C}$ (Table 2). The molds found in bathroom samples were predominantly Exophiala sp., Scolecobasidium sp., and Phoma sp., followed by Cladophialophora sp., Fusarium sp., and Acremonium sp. Meanwhile, the

TABLE 2. Fungal flora in culture at $25^{\circ} \mathrm{C}$ and at $37^{\circ} \mathrm{C}$.

\begin{tabular}{|c|c|c|c|c|c|c|c|}
\hline \multirow[b]{2}{*}{ Temp. } & \multirow[b]{2}{*}{ Genus } & \multirow{2}{*}{$\begin{aligned} & \text { Bathroom } \\
\geqq & 100 \mathrm{cfu} / \mathrm{cm}^{2}\end{aligned}$} & \multicolumn{5}{|c|}{ Sink } \\
\hline & & & Log (avg. \pm s.e.) & Average & $\geqq 1000 \mathrm{cfu} / \mathrm{cm}^{2}$ & Log (avg. \pm s.e.) & Average \\
\hline \multirow{15}{*}{$25^{\circ} \mathrm{C}$} & Total mold & 27 & $3.50 \pm 0.12$ & 3190 & 21 & $2.39 \pm 0.16$ & 244 \\
\hline & Acremonium & 1 & $1.15 \pm 0.08$ & 14.1 & 1 & $1.04 \pm 0.03$ & 11.0 \\
\hline & Aspergillus & 0 & $1.00 \pm 0.00$ & 10.0 & 0 & $1.00 \pm 0.00$ & 10.0 \\
\hline & Aureobasidium & 0 & $1.03 \pm 0.03$ & 10.8 & 0 & $1.00 \pm 0.00$ & 10.0 \\
\hline & Cladosporium & 1 & $1.14 \pm 0.07$ & 13.8 & 2 & $1.11 \pm 0.05$ & 12.8 \\
\hline & Cladophialophora & 3 & $1.31 \pm 0.11$ & 20.6 & 0 & $1.00 \pm 0.00$ & 10.0 \\
\hline & Exophiala & 10 & $2.41 \pm 0.16$ & 255.0 & 16 & $1.98 \pm 0.16$ & 96.6 \\
\hline & Fusarium & 0 & $1.23 \pm 0.09$ & 16.9 & 2 & $1.22 \pm 0.08$ & 16.7 \\
\hline & Paecilomyces & 0 & $1.02 \pm 0.02$ & 10.4 & 0 & $1.03 \pm 0.03$ & 10.8 \\
\hline & Penicillium & 0 & $1.00 \pm 0.00$ & 10.0 & 0 & $1.00 \pm 0.00$ & 10.1 \\
\hline & Phialophora & 0 & $1.14 \pm 0.07$ & 13.9 & 0 & $1.00 \pm 0.00$ & 10.0 \\
\hline & Phoma & 4 & $1.64 \pm 0.14$ & 43.8 & 2 & $1.16 \pm 0.08$ & 14.6 \\
\hline & Scolecobasidium & 6 & $2.05 \pm 0.17$ & 113.4 & 2 & $1.13 \pm 0.06$ & 13.5 \\
\hline & Other mold & 0 & $1.00 \pm 0.00$ & 10.0 & 1 & $1.05 \pm 0.05$ & 11.2 \\
\hline & Unknown mold & 0 & $1.12 \pm 0.06$ & 13.3 & 2 & $1.10 \pm 0.06$ & 12.7 \\
\hline Temp. & Genus & $\geqq 100 \mathrm{cfu} / \mathrm{cm}^{2}$ & Log (avg. \pm s.e.) & Average & $\geqq 1000 \mathrm{cfu} / \mathrm{cm}^{2}$ & Log (avg. \pm s.e.) & Average \\
\hline \multirow{15}{*}{$37^{\circ} \mathrm{C}$} & Total mold & 8 & $0.70 \pm 0.11$ & 5.0 & 7 & $0.77 \pm 0.12$ & 5.9 \\
\hline & Acremonium & 0 & $0.03 \pm 0.03$ & 1.1 & 0 & $0.00 \pm 0.00$ & 1.0 \\
\hline & Aspergillus & 0 & $0.01 \pm 0.01$ & 1.0 & 0 & $0.08 \pm 0.03$ & 1.2 \\
\hline & Aureobasidium & 0 & $0.00 \pm 0.00$ & 1.0 & 0 & $0.00 \pm 0.00$ & 1.0 \\
\hline & Cladosporium & 0 & $0.00 \pm 0.00$ & 1.0 & 0 & $0.00 \pm 0.00$ & 1.0 \\
\hline & Cladophialophora & 0 & $0.00 \pm 0.00$ & 1.0 & 0 & $0.00 \pm 0.00$ & 1.0 \\
\hline & Exophiala & 3 & $0.23 \pm 0.07$ & 1.7 & 6 & $0.43 \pm 0.12$ & 2.7 \\
\hline & Fusarium & 2 & $0.13 \pm 0.06$ & 1.4 & 0 & $0.12 \pm 0.05$ & 1.3 \\
\hline & Paecilomyces & 0 & $0.04 \pm 0.03$ & 1.1 & 0 & $0.02 \pm 0.02$ & 1.0 \\
\hline & Penicillium & 0 & $0.01 \pm 0.01$ & 1.0 & 0 & $0.04 \pm 0.02$ & 1.1 \\
\hline & Phialophora & 1 & $0.05 \pm 0.05$ & 1.1 & 0 & $0.00 \pm 0.00$ & 1.0 \\
\hline & Phoma & 1 & $0.05 \pm 0.04$ & 1.1 & 0 & $0.01 \pm 0.01$ & 1.0 \\
\hline & Scolecobasidium & 0 & $0.00 \pm 0.00$ & 1.0 & 0 & $0.00 \pm 0.00$ & 1.0 \\
\hline & Other mold & 0 & $0.08 \pm 0.04$ & 1.2 & 0 & $0.08 \pm 0.04$ & 1.2 \\
\hline & Unknown mold & 0 & $0.08 \pm 0.04$ & 1.2 & 1 & $0.07 \pm 0.04$ & 1.2 \\
\hline
\end{tabular}

Average mold count is expressed as the average of $\mathrm{cfu} / \mathrm{cm}^{2}$. 
average number of Fusarium sp. in sink samples was similar to that in bathroom samples, but the average values for the other predominant fungi, for example Exophiala sp., Scolecobasidium sp., and Phoma sp., were lower in sinks than in bathrooms.

Under culture at $37^{\circ} \mathrm{C}$, fungi of several genera, including Exophiala sp. and Fusarium, sp. were found in bathroom samples; four genera were found at fungal counts of more than $100 \mathrm{cfu} / \mathrm{cm}^{2}$ (Table 2).
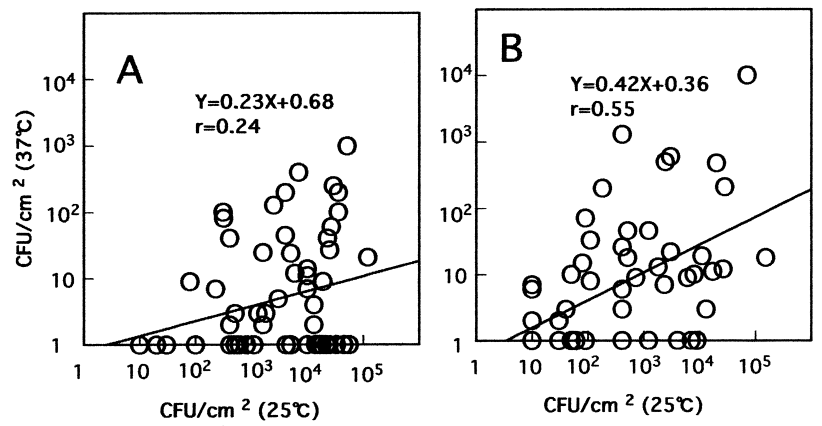

FIG. 1. Fungal counts after culture at $25^{\circ} \mathrm{C}$ and $37^{\circ} \mathrm{C}$. Fungi were collected from the drainpipes of bathrooms (A) or kitchens (B) in 62 dwellings during autumn.

The plot shows mold counts detected on media after culture at $25^{\circ} \mathrm{C}$ and $37^{\circ} \mathrm{C}$.
However, the only fungus with a count of $100 \mathrm{cfu} / \mathrm{cm}^{2}$ in sink samples was Exophiala sp. Apart from the genera described in Table 2, Alternaria sp., Mucor sp., Ramichloridium sp., Cyphellophora sp., and Bauveria sp. were found in bathroom or sink samples at counts of more than $10 \mathrm{cfu} / \mathrm{cm}^{2}$.

Mold isolated and cultured on a slant was examined microscopically. The fungi detected at $37^{\circ} \mathrm{C}$ were identified morphologically using a fungus monograph (de Hoog et al., 2000).

The predicted size fragment (approximately 500$600 \mathrm{bp}$ ) was amplified using PCR in mold isolates (data not shown). Homology searching of the partial sequences showed that the sequences of isolates JCM16197, 16198, 16199, 16200, 16201, 16202 , 16203, 16204, 16205, 16206, and 16207 had homology of $99.8 \%, 100 \%, 100 \%, 99.3 \%, 100 \%, 100 \%$, $100 \%, 100 \%, 99.5 \%, 100 \%$, and $100 \%$ with Fusarium solani, Fusarium sp., Phoma glomerata, Phialophora verrucosa, Exophiala dermatitidis, E. dermatitidis, E. dermatitidis, E. dermatitidis, E. dermatitidis, E. dermatitidis, and E. dermatitidis, respectively (Table 3). Although two strains of Exophiala sp. were not examined genetically, they were also identified morphologically as E.dermatitidis.

Only E. dermatitidis, all of the nine strains, was

TABLE 3. List of fungal strains growing well at $37^{\circ} \mathrm{C}$

\begin{tabular}{lcccc}
\hline Fungal species & JCM\# & Accession\# & Collection site & Growth at $40^{\circ} \mathrm{C}$ \\
\hline Fusarium solani & 16197 & 498917 & bathroom & no \\
Fusarium sp. & 16198 & 498918 & bathroom & no \\
Phoma glomerata & 16199 & 498919 & bathroom & no \\
Phialophora verrucosa & 16200 & 498920 & bathroom & no \\
Exophiala dermatitidis & 16201 & 498921 & bathroom & yes \\
Exophiala dermatitidis & 16202 & 498922 & bathroom & yes \\
Exophiala dermatitidis & 16203 & 498923 & bathroom & yes \\
Exophiala dermatitidis & 16204 & 498924 & sink & yes \\
Exophiala dermatitidis & 16205 & 498925 & sink & yes \\
Exophiala dermatitidis & 16206 & 498926 & sink & yes \\
Exophiala dermatitidis & 16207 & 498927 & sink & yes \\
\hline
\end{tabular}

Molds with population of 100 or more were identified and cultured at $40^{\circ} \mathrm{C}$.

TABLE 4. Effects of three surfactants on the growth of Exophiala dermatitidis

\begin{tabular}{lccccccccc}
\hline \multicolumn{1}{c}{ Content } & $\begin{array}{c}0.01 \% \\
\text { Fungal }\end{array}$ & & & $0.05 \%$ & & \multicolumn{2}{c}{$0.25 \%$} \\
Surfactant & count & Color & Size & coungal & Color & Size & Fungal count & Color & Size \\
\hline SO (sodium fatty acid) & 75 & \pm & + & 78 & dark & + & 76 & + \\
AE (nonion surfactant) & 76 & \pm & + & 61 & gray & + & 63 & + \\
LAS (anion surfactant) & 81 & gray & & 0 & & & 0 & + \\
\hline
\end{tabular}

Fungal count indicates total of colonies detected on two Petri dishes.

Suspensions of fungal spores collected from slants were diluted 10,000 times.

Fungal count on $1 / 4 \mathrm{PDA}$ at $25^{\circ} \mathrm{C}$ was 79 for E. dermatitidis.

Color of fungi compared with that in $0.05 \%$ SO or AE and expressed as follows: + : same; \pm : lighter

Size of colony compared with that in $0.05 \%$ SO or AE and expressed as follows: + : same: \pm : smaller. 
found to grow at $40^{\circ} \mathrm{C}$.

The growth characteristics of $E$. dermatitidis (JCM16201) were examined in media containing surfactant of three kinds (Table 4). Colonies of this species were detected in media of $0.01 \%$ LAS within 10 days, as well as in SO and AE media. Fungal counts on $0.01 \%$ media of $S O, A E$, and LAS resembled those on 1/4 PDA. Colony counts of this species were similar at all surfactant concentrations, except for $0.05 \%$ and $0.25 \%$ LAS, at which no colony was found.

In two of the surfactants, colonies of E. dermatitidis were darker in $0.05 \%$ and $0.25 \%$ media than in $0.01 \%$ media. The size of colonies in SO and AE media was similar at all three concentrations.

At $37^{\circ} \mathrm{C}$ and $40^{\circ} \mathrm{C}$, only E. dermatitidis was found to grow prolifically, although other species of pathogenic Exophiala have been reported previously in bathroom samples (Nishimura et al., 1987). In bathrooms and sinks, the main pathogenic fungus was thought to be E. dermatitidis. Fusarium solani and the neurotrope E. dermatitidis are also known to be clinical fungi (de Hoog et al., 2000). A number of pathogenic fungi were thus confirmed to grow in bathrooms.

Hot water is used more frequently in bathrooms than in sinks. Moreover, the present survey was carried out in autumn, when hot water is little used in sinks. Nevertheless, fungal counts were similar in bathroom and sink samples cultured at $37^{\circ} \mathrm{C}$. In culture at $25^{\circ} \mathrm{C}$, however, fungal counts were more than ten times greater in bathroom than in sink samples (Table 2). Hot water seems thus to be ineffective as a selection pressure to increase the thermotolerant fungi $E$. dermatitidis in bathrooms.

In a previous study using fungi cultured at $25^{\circ} \mathrm{C}$ (Hamada and Abe., 2009), the predominant strains of Exophiala sp. on bathroom walls and floors were $E$. spinifera and $E$. salmonis, with no colony of $E$. dermatitidis detected, although the latter was also found to grow at $25^{\circ} \mathrm{C}$ in this study. As fungal counts in bathroom samples grown at $37^{\circ} \mathrm{C}$ were only $1 / 600$ of those in samples grown at $25^{\circ} \mathrm{C}$ in the present study (Table 2), E. dermatitidis, along with $E$. spinifera and $E$. salmonis, is thought to be a minor species.

The present results seem to differ from the findings of a study by Nishimura et al. (1987) which reported the collection of thermotolerant fungi from bathwater after bathing and from drainpipes. E. dermatitidis has also been found in a humidifier (Nishimura and Miyaji, 1982) and a sauna (Matos et al., 2002), where obviously hot and humid conditions prevail. However, these studies isolated fungi growing under hot conditions only, ignoring the numerous fungi that grow at $25^{\circ} \mathrm{C}$. The present study suggests that thermotolerant fungi are not common on bathroom walls or floors. Cultivation at various temperatures is thus necessary to ascertain comprehensively the fungal flora of bathroom environments.

Exophiala sp., Scolecobasidium sp., and Phoma sp., unlike Fusarium sp., seem to use the nonion surfactant component of detergents as a nutrient. As detergent appears to be used more frequently in bathrooms than in sinks, the counts of Exophiala sp., Scolecobasidium sp. and Phoma sp., as well as the total mold counts, were higher in bathroom than in sink samples (Table 2).

Exophiala dermatitidis grown on $0.25 \% \mathrm{AE}$ or $0.25 \%$ SO media seems to use shampoo and soap and is thought to grow in the presence of detergent. The environmental factors promoting the growth of $E$. dermatitidis may include not only heat but also the availability of detergent.

Hot water is used with varying frequency in several areas of the home apart from the bathroom, but all parts of heated dwellings may host thermotolerant fungi.

\section{ACKNOWLEDGEMENTS}

I would like to express a deep appreciation to Mr. Nakatsuka, Noritzu Co. and Mr. Fukatzu, Idemitsu Techno-fine Co. for the help of examination and valuable suggestions.

\section{REFERENCES}

de Hoog, G. S., Guarro, J., Gene, J., and Figueras, M. J. (2000) Atlas of Clinical Fungi, 2nd edn., Centraalbureau voor Schimmelcultures, Utrecht.

Hamada, N. (2005) Characteristics of fungal growth inside washing machines (in Japanese), Seikatsu Eisei, 49, 108-113.

Hamada, N. (2008) Effect of cleaning on fungal contamination in bathrooms (in Japanese), Seikatsu Eisei, 52, 159168.

Hamada, N., and Abe, N. (2008) Characteristics of recent fungal contamination in bathrooms: examination of fungal and yeasty flora (in Japanese), Seikatsu Eisei, 52, 98106.

Hamada, N., and Abe, N. (2009) Physiological characteristics of 13 common fungal species in bathrooms, Mycoscience, 50, 421-429.

Hamada, N., and Fujita, T. (2000) Growth rate of fungi in bathrooms: experimental survey, Mycoscience, 41, 297301.

Hamada, N., Murakami, T., and Abe, N. (2006) Characteristics of fungi growing on window sashes, Seikatsu Eisei, 50, 510-515.

Matos, T., de Hoog, G.S., de Boer, A.G., de Crom, I., and Haase, G. (2002) High prevalence of the neurotrope Exophiala dermatitidis and related oligotrophic black 
yeasts in sauna facilities, Mycoses, 45, 373-377.

Moriyama, Y., Nawata, N., Tsuda, T., and Nitta, M. (1992)

Occurrence of moulds in Japanese bathrooms, International Biodeterioration \& Biodegradation, 30, 4755.

Nishimura, K., and Miyaji, M. (1982) Studies on a saprophyte of Exophiala dermatitidis isolated from a humidifier,
Mycopathologia, 77, 173-181.

Nishimura, K., Miyaji, M., Taguchi, H., and Tanaka, R. (1987) Fungi in bathwater and sludge of bathroom drainpipes, Mycopathologia, 97, 17-23.

Zak, J.C., and Wildman, H.G. (2004) Fungi in stressful environments. In Biodiversity of Fungi (Mueller, D. M. et al., ed.), pp. 303-315, Elsevier, Burlington. 